\title{
Mortality associated with burn injury- a cross sectional study from Karachi, Pakistan
}

Ehmer al Ibran ${ }^{1}$, Farhat Hussain Mirza ${ }^{2}$, Akhtar Amin Memon ${ }^{3 *}$, Muhammad Zain Farooq ${ }^{3}$ and Maryum Hassan ${ }^{3}$

\begin{abstract}
Background: Burn injuries are a major cause of medico legal deaths in Pakistan. The present study was conducted with the aim to assess the mortality rate related to different types of burns injuries.

Findings: This was an observational prospective cross sectional study conducted in Burns Ward of Civil Hospital, Karachi during a period of two years from January $1^{\text {st }} 2010$ to December $31^{\text {st }}, 2011$. Data was collected over a questionnaire containing demographic variables as well as date of burn, date of the death (if patient expired), total body surface area involved, cause and manner of burn. The data was statistically analyzed by SPSS v. 16. A total of 1979 patients were admitted to the department during the study period. Out of them, 715 died, hence a mortality rate of $36.12 \%$. Out of the 715 patients, $380(53.1 \%)$ were males and 335 (46.9\%) were females. Mortality was highest in age-group 16-30 years $(n=395,55.2 \%)$. Majority of the deaths were accidental $(n=685,95.8 \%)$. Fire burns was found to be the most common cause of death $(n=639,89.3 \%) .35 \%(n=252)$ of the patients who died had more than $60 \%$ of total body surface area involved in burns.
\end{abstract}

Conclusion: Measures must be taken to inform the general population of the possible causes of these injuries, and to enable the people to be prepared to face any such circumstances.

Keywords: Burn Injury, Mortality

\section{Introduction}

Burn injuries pose a high burden of fatalities on the health systems worldwide. About $90 \%$ of burn incidents occur in low to middle income countries, areas that are deficient in the essential means to decrease the rate and intensity of such injuries [1].

In United States, the mortality rate in relation to burn injuries was 5.3\%, with higher age groups and greater-\% total body surface area (TBSA) burned associated with greater fatality rates [2].

The reported mortality rate due to burns in different Asian countries is variable. Sharma et al. reported a relatively low annual mortality rate of 0.6 per 100,000 in Kuwait [3]. Mashreky et al. reported a mortality rate of about 2.2 per 100,000 in Bangladesh in the year 2011 [4]. A study from Iran reported an annual fatality rate of 5.6 deaths per 100,000 [5]. In 2004 only, the death rate due to burns in Iraq was reportedly 12.3 per 100,000 , much higher than rate worldwide [6]. Such high rate

\footnotetext{
* Correspondence: akhtar.amin@live.com

${ }^{3}$ Dow Medical College, Dow University of Health Sciences, Karachi, Pakistan

Full list of author information is available at the end of the article
}

was on account of the war in Iraq that began in 2004. A study from India reported an even higher mortality rate of about 15.1 per 100,000 in year 2003 [7]. It further reported suicide commitment by females to be a major contributor to the death rate [7].

The objective of our current study is to determine the fatality rate of burn patients in Karachi, the largest city of Pakistan. Our study has been conducted on the base of available data at the only major burn centre of the city, where there are maximum reported burn cases than any other healthcare centre. We also aim to assess the effect of cause of burn cases, type of burns, and the total body surface area (TBSA) involved in related to mortality in burn patients.

\section{Findings}

This cross sectional descriptive study was conducted at the Burns Ward of Civil Hospital, Karachi over a period over a period of two years from January $1^{\text {st }} 2010$ to December $31^{\text {st }}, 2011$. 
A total of 1979 patients were admitted at the burns centre during the study duration including 57\% males $(n=1129)$ and $43 \%$ females $(n=850)$.

A preformed questionnaire was filled for each patient that included demographics like age, gender, type of burn, cause of burn, date of birth, date of death (if patient expired) and TBSA (total burnt surface area).

The data was entered and analyzed on SPSS version 16. Frequency and percentages were calculated for qualitative variables whereas means, standard deviations were calculated for quantitative variables. P-values were calculated to determine the significance of the data (using Pearson Chi Square Test). The study was approved by the Ethical Review Board of the Dow University of Health Sciences, Karachi, Pakistan.

\section{Results}

Out of 1979 patients admitted to the department during the study period, 715 died with a mortality rate of $36.12 \%$. Reported males $(n=380,53.1 \%)$ were significantly higher than females 335 (46.9\%). Incidence was reported to be higher in females $(n=853)$, being $39.4 \%$ of the admitted female. In males, the death rate was comparatively less, being $33.6 \%$ of the 1129 males admitted [Table 1].

Mortality was higher in the age group between 16-30 years $(\mathrm{n}=395,55.2 \%)$. It was also significant in age group 61 years and above where out of $n=71$ patients, 34 died $(47.8 \%)$ as shown in Table 1 . The youngest patient to die of the burn injury was a two year old male while oldest were two adults, one male and one female, each of 90 years respectively.

In the cases of accidental burns $(n=685) 95.8 \%$ of the patients died; whereas in the cases of suicide $(n=36), 24$ died; giving a death rate of $66.67 \%$ [Table 1].

Fire burns was found to be the most common cause of death $(n=639,89.3 \%)$. It was also the one with highest death rate of about $39.7 \%$ [Table 1 ].

Overall, majority $(n=252,35 \%)$ of the patients who died had $61 \%$ or more the TBSA involved. Furthermore, out of the 317 patients with TBSA $61 \%$ or greater, $79.5 \%$ died. On applying linear regression analysis, strong correlation was found between burn area of the body (TBSA) and mortality i.e. $1.8 \%$ with $1 \%$ increase in TBSA [Table 1].

\section{Discussion}

We report a mortality rate of about $36 \%$ due to burn injuries in Karachi, Pakistan during our study duration. Burn injuries are associated with $5 \%$ of mortality globally. About 500 billion US $\$$ is the overall expense per annum related to burn injuries [8].

Globally, several studies have reported mortality rate due to burn injuries. Olaitan et al. reported a $20 \%$ mortality
Table 1 Demographics, cause of burn, type of burn and TBSA in relation to mortality rate

\begin{tabular}{|c|c|c|c|c|}
\hline & \multicolumn{2}{|c|}{ Patient prognosis } & \multirow[b]{2}{*}{ Total } & \multirow[b]{2}{*}{ P-Value } \\
\hline & Alive & Dead & & \\
\hline Frequency: & 1129 & 715 & 1979 & \\
\hline \multicolumn{5}{|l|}{ Gender: } \\
\hline Male & 749 (66.4\%) & 380 (33.6\%) & 1129 (100\%) & \multirow[t]{2}{*}{0.008} \\
\hline Female & $515(60.6 \%)$ & $335(39.4 \%)$ & $850(100 \%)$ & \\
\hline \multicolumn{5}{|l|}{ Age groups: } \\
\hline$\geq 15$ years & $236(82.5 \%)$ & $50(17.5 \%)$ & $286(100 \%)$ & \multirow[t]{5}{*}{0.000} \\
\hline 16-30 years & $639(61.8 \%)$ & 395 (38.2\%) & $1034(100 \%)$ & \\
\hline $31-45$ years & $262(59.8 \%)$ & $176(40.2 \%)$ & $438(100 \%)$ & \\
\hline $46-60$ years & $90(60 \%)$ & $60(40 \%)$ & $150(100 \%)$ & \\
\hline 61 years $\leq$ & $37(52.1 \%)$ & $34(47.9 \%)$ & $71(100 \%)$ & \\
\hline \multicolumn{5}{|l|}{ Cause of burn: } \\
\hline Accidental & $1241(64.4 \%)$ & $678(35.3 \%)$ & 1919 (100\%) & \multirow[t]{3}{*}{0.000} \\
\hline Homicidal & $11(45.8 \%)$ & $13(54.2 \%)$ & $24(100 \%)$ & \\
\hline Suicidal & $12(33.3 \%)$ & $24(66.7 \%)$ & $36(100 \%)$ & \\
\hline \multicolumn{5}{|l|}{ Type of burn: } \\
\hline Fire burn & 969 (60.3\%) & 639 (39.7\%) & 1608 (100\%) & \multirow[t]{5}{*}{0.000} \\
\hline Electric burn & $150(81.5 \%)$ & $34(18.5 \%)$ & $184(100 \%)$ & \\
\hline Chemical burn & $41(70.7 \%)$ & $17(29.3 \%)$ & $58(100 \%)$ & \\
\hline Scaled burn & $88(81.5 \%)$ & $20(18.5 \%)$ & 108 (100\%) & \\
\hline Flash burn & $16(76.2 \%)$ & $5(23.8 \%)$ & $21(100 \%)$ & \\
\hline \multicolumn{5}{|l|}{ TBSA: } \\
\hline$\geq 10 \%$ & 301 (86.7\%) & $46(13.3 \%)$ & 347 (100\%) & \multirow[t]{5}{*}{0.000} \\
\hline $11-20 \%$ & 381 (86.8\%) & $58(13.2 \%)$ & 439 (100\%) & \\
\hline $21-40 \%$ & 408 (68.2\%) & 190 (31.8\%) & $598(100 \%)$ & \\
\hline $41-60 \%$ & 109 (39.2\%) & 169 (60.8\%) & 278 (100\%) & \\
\hline $61 \% \leq$ & 65 (20.5\%) & 252 (79.5\%) & $317(100 \%)$ & \\
\hline
\end{tabular}

rate in Osogbo, Nigeria [9]. A study from Rotterdam, Netherlands reported a fatality rate of $6.9 \%$ [10]. Similarly, Aldemir et al. from Turkey reported a death rate of $6.3 \%$ [11].

A study from Wah, Pakistan reported $29.7 \%$ death rate in burn patients [12]. Muqim et al. from Peshawar, Pakistan reported 19\% [13], while Chaudhry IA reported about $21 \%$ burn fatality rate from Rawalpindi, Pakistan [14]. Our study has reported by far, the highest mortality rate. Karachi, being the largest and most populated city in Pakistan, and being the economic hub of the country, such high rates are troublesome.

Males are more usually victims of burn injuries as is evident by our study. However, female tend to have a higher mortality rate. Mortality was also high in age group more than 60 years, where about $47 \%$ patients expired. This is consistent with another study by Chaudhry IA [14].

TBSA was a significant association with death of patients, where about $80 \%$ patients with TBSA greater than 
$60 \%$ died. It corroborates and even surpasses the rate reported earlier by O'Mara et al. where 70\% of patients with TBSA greater than 60\% died [15]. A study in Pakistan also reported 50\% TBSA, above which all the cases involved died [12].

Majority of the deaths in our patients was due to accidental causes, fire burns being the most common type. We should provide awareness of proper first aid responses that may prevent such cases to aggravate. Also, fire extinguishers should be made available at more places and people should be provided with awareness of their use.

\section{Competing interests}

The authors declare that they have no competing interests.

\section{Authors' contributions}

MFH gave the idea of the study. IEA and MAA designed the study. MAA, FZ, HM prepared the synopsis for IRB approval. MFH and IEA reviewed and edited the synopsis. FZ and HM collected the data and entered in on SPSS. MAA analyzed the data on SPSS. MAA wrote the initial draft of manuscript. All authors reviewed and edited the manuscript. All authors read and approved the final manuscript.

\section{Author details}

'Civil Hospital Karachi, Dow University of Health Sciences, Karachi, Pakistan. ${ }^{2}$ Department of Forensic Medicine, Dow Medical College, Dow University of Health Sciences, Karachi, Pakistan. ${ }^{3}$ Dow Medical College, Dow University of Health Sciences, Karachi, Pakistan.

Received: 25 February 2013 Accepted: 13 December 2013

Published: 19 December 2013

\section{References}

1. Murray CJL, Lopez AD: The global burden of disease: a comprehensive assessment of mortality and disability from diseases, injuries, and risk factors in 1990 and projected to 2020. Swizerland: World Health Organization; 2006.

2. Latenser BA, Miller SF, Bessey PQ, Browning SM, Caruso DM, Gomez M, et al: National burn repository 2006: a ten-year review. J Burn Care Res 2007, 28(5):635-658.

3. Sharma PN, et al: Predicting factors influencing the fatal outcome of burns in Kuwait. Burns 2005, 31(2):188-192.

4. Mashkarey SR, Rahman A, Svanstrom L, Khan TF, Rahman F: Burn mortality in Bangladesh: findings of national health and injury survey. Injury 2011, 42(5):507-510.

5. Maghsoudi H, Pourzand A, Azarmir G: Etiology and outcome of burns in Tabriz, Iran. An analysis of 2963 cases. Scand J Surg 2005, 94(1):77-81.

6. WHO: Annual incidence (000s) for selected causes, in WHO Regions (a), estimates for 2004. [online] 2004 [cited 2009 June 20]; Available from http:// www.who.int/healthinfo/global_burden_disease/estimates_regional/en/ index.html.

7. Batra AK: Burn mortality: recent trends and sociocultural determinants in rural India. Burns 2003, 29(3):270-275.

8. Nordberg E: Injuries as a public health problem in Sub-Saharan Africa: epidemiology and prospect for control. East Afr Med J 2000, 77:1-4.

9. Olaitan PB, Jiburum BC: Analysis of burn mortality in a burns centre. Ann Burns Fire Disasters 2006, 19(2):59-62.

10. Bloemsma GC, Dokter J, Boxma H, Oen IM: Mortality and causes of death in a burns centre. Burns 2008, 34(8):1103-1107.

11. Aldemir M, Kara $H$, Girgin S, Guloglu C: Factors affecting mortality and epidemiological data in patients hospitalized with burns in Diyarbakir, Turkey. S Afr J Surg 2005, 43(4):159-162.

12. Khan N, Malik MA: Presentation of burn injuries and their management outcome. J Pak Med Assoc 2006, 56:394-397.
13. Muqim R, Zareen M, Dilbag, Hayat M, Khan I: Epidemiology and outcome of burns at Khyber teaching hospital Peshawar. Pak J Med Sci 2007, 23:420-424.

14. Chaudhry IA: Burns: frequency and mortality related to various age groups. J Surg Pak 2009, 14(2):67-71.

15. O'Mara MS, Caushaj P, Goldfarb IW, Slater H: Treatment and mortality trends among massively burned patients. Ann Burns Fire Disasters 2000, 13(2):73.

doi:10.1186/1756-0500-6-545

Cite this article as: Ibran et al:: Mortality associated with burn injury- a cross sectional study from Karachi, Pakistan. BMC Research Notes

2013 6:545.

\section{Submit your next manuscript to BioMed Central and take full advantage of:}

- Convenient online submission

- Thorough peer review

- No space constraints or color figure charges

- Immediate publication on acceptance

- Inclusion in PubMed, CAS, Scopus and Google Scholar

- Research which is freely available for redistribution 